\title{
MEDICINA DE URGÊNCIA NO BRASIL: AONDE VAMOS?
}

Dr. Greene chega ao plantão no prontosocorro. Já na entrada, ajuda a dar atendimento inicial a um politraumatizado, drenando seu pneumotóraxhipertensivo. Aseguir, atendee tromboliza um infartado, diagnostica e indica cirurgia num abdome agudo, ressuscita uma vítima de morte súbita e faz o parto de uma paciente que chegou já em período expulsivo, sem que houvesse tempo de localizar um obstetra. Dr. Greene é o EP (Emergency Physician) da série de televisão ER, e espelha com propriedadeasatividades do emergencista num hospital público americano.

Segundo dados do American College of Emergency Physicians (ACEP), o primeiro programa de Residência Médica em Medicina de Urgência dos Estados Unidos foi implantado em 1970, na University of Cincinatti. Em janeiro de 1972, foi publicado o primeiro JACEP, que, em 1980, veio a se tornar o Annals of Emergency Medicine, hoje o principal periódico específico de Medicina de Urgência. Em junho de 1976, formou-se o American Board of Emergency Medicine e, em setembro de 1979, a Medicina de Urgência passou a ser considerada uma especialidade médica pelo American Board of Medical Specialties e pela AMA. Em maio de 1980, os primeiros emergencistas foram certificados pelo American Board of Emergency Medicine. Atualmente, existem mais de 21 mil médicos associados ao ACEP, e estimou-se em quase 107 milhões o volume de atendimentos em prontos-socorros nos EUA no ano de 2000.

Estes dados dão uma idéia da importância dada à formação de um médico generalista, especializado e com vasta experiência no atendimento de urgências, tanto clínicas como cirúrgicas, em um país desenvolvido, com rede básica de saúde adequada e fácil acesso a consultas e tratamentos ambulatoriais. Também mostra a necessidade de um profissional experiente e bem formado para fazer frente ao volume de atendimentos de urgência que o país necessita.

E nós, como estamos? A situação é bem diferente. No ano de 2002, foram realizados cerca de 48 milhões de atendimentos pelo SUS em prontos-socorros no País, com mortalidade alta. Destes, um número expressivoé de doentes em estado crítico, mas que não teriam chegado ao PS se tivessem recebido tratamento médico adequado previamente. A taxa de internação hospitalar destes doentes é muito baixa, devido à carência de leitos na rede, gerando "internação" em macas durante dias, fato que todos nós já vivenciamos nos hospitais públicos.

Quem atende estes doentes? Certamente não é um profissional estigmatizado na figura do Dr. Greene. Os plantonistas de prontossocorros em nosso país geralmente são profissionais em início de carreira, ou ainda em formação, com pouca experiência. Além disso, são mal remunerados e sofrem com uma carga de trabalho brutal, o que piora ainda mais a situação. Embora alguns Estados tenham iniciado um movimento para a criação de Sociedades de Medicina de Urgência, não existe ainda o embrião da especialidade enem mesmo a definição do perfil do que deveria ser o nosso emergencista.

Nos hospitais universitários a situação muda pouco. O panorama físico é o mesmo: longos corredores ou saguões lotados de macas. A assistência médica é consideravel- mente mais diferenciada, sendo estabelecimentos voltados ao ensino. $O$ atendimento é supervisionado por professores ou por profissionais com vivência em urgências, entretanto, nota-se cada vez mais uma distorção na formação: a "especialização" dos PS. Hoje, temos o PS de Clínica Médica, Cirurgia, Ortopedia, Neuro, Pediatria, Obstetrícia/GO, Otorrino, Oftalmo e outros mais. $O$ aluno passa por eles em estágios distintos, fragmentando o ensino ao invés de integrar, indo de encontro à tendência mundial de formação do médico emergencista. Hoje ele sabe diagnosticar oAVC, porém não sabe tratar a hipertensão; amanhã, tratará a crise hipertensiva, mas não veráa hemiplegia do paciente. Poucas são as tentativas de formação de uma disciplina que ensine Medicina de Urgência de uma forma sistemática. A primeira foi criada na Faculdade de Medicina da USP, que hoje contempla o ensino de Graduação, Residência e Pós-graduação strictu sensu e lato sensu. Entretanto, de nosso conhecimento, é a única disciplina com esta estrutura no Brasil. Será isso o desejável? Certamente que não.

Aonde vamos então? Difícil dizer, mas por enquanto para lugar nenhum. As Universidades, grandes formadoras de opinião, ainda não deram o passo inicial com a unificação dos Serviços de Urgência e sua transformação numa disciplina única. A rede pública ainda remunera mal seus médicos e o PS atrai apenas o jovem, enquanto este não arranja emprego melhor. Enquanto não passarmos a encarar estes fatos com seriedade e fizermos algo para transformá-los, conformemo-nos: Dr. Greene só existirá para nós em seriados de televisão. 